\title{
CONTRA O MÉTODO APAC: "NOVAS" ALTERNATIVAS NA EXECUÇÃO PENAL
}

Dani Rudnicki*

\begin{tabular}{l|l}
\hline RECEBIDO EM: & 7.11 .2021 \\
\hline APROVADO EM: & 3.12 .2021 \\
\hline
\end{tabular}

* Graduado em Ciências Jurídicas e Sociais pela Universidade Federal do Rio Grande do Sul (UFRGS) e em Comunicação Social pela Pontifícia Universidade Católica do Rio Grande do Sul (PUCRS), mestre em Direito pela Universidade do Vale do Rio dos Sinos (Unisinos) e doutor em Sociologia pela UFRGS. Professor e coordenador adjunto do Programa de Pós-Graduação em Direito da Universidade La Salle, campus de Canoas. Atua no Instituto Nacional de Estudos e Pesquisas Educacionais Anísio Teixeira (Inep) como avaliador de curso. Tem experiência na área de direito, com ênfase em direito penal e sociologia da violência (pesquisa sobre polícia e presídios).E-mail: danirud@ hotmail.com 
- Resumo: Perante a crise do sistema penitenciário, surgem ideias para repensá-lo. A Igreja Católica, por meio da Pastoral Carcerária, da Conferência Nacional dos Bispos do Brasil e da Associação de Proteção e Assistência ao Condenado (Apac), apresenta propostas diversas e antagônicas. Neste artigo, analisam-se, com base em Foucault, as informações contidas em documentos, teses, dissertações e sites. Para tanto, utiliza-se o método dialético. Percebe-se que o método Apac se apresenta como uma prisão diferente, impondo a obrigação de o preso ter bom comportamento comprometido com a ressocialização. A Pastoral Carcerária propõe uma intervenção diversa: critica o aumento da população carcerária e a ineficácia da pena restritiva de liberdade. As informações mostram que a prisão adestra e que também na Apac há submissão do corpo. Assim, o método Apac não defende os direitos humanos.

palavras-chave: Direitos humanos; prisão; Pastoral Carcerária.

\section{AGAINST THE APAC METHOD: “NEW” ALTERNATIVES IN} CRIMINAL ENFORCEMENT

- ABSTRACT: Faced with the crisis in the penitentiary system, ideas for rethinking it arise. The Catholic Church, through the Prison Ministry, the National Conference of Bishops of Brazil and the Association for the Protection and Assistance of the Convicted (Apac), presents diverse, antagonistic proposals. This article uses information contained in documents, theses, dissertations and website information; they are studied based on Foucault, using the dialectical method. It is noticed that the Apac method presents itself as a different prison, imposing the obligation of the prisoner to have good behavior committed to resocialization. Prison Ministry proposes a different intervention: it criticizes the increase in the prison population and the ineffectiveness of the penalty restricting freedom. The information shows that prison trains and that in Apac there is also submission of the body. Thus, the Apac method does not defend human rights.

- KeYwords: Human rights; prison; Prison Ministry. 


\section{Introdução}

Estudiosos do sistema penitenciário brasileiro declaram que ele está falido e mencionam a necessidade de sua substituição (BITENCOURT, 1993; THOMPSON, 1993). Outros, estrangeiros, entendem que a ideia de encarcerar é simples reflexo de um modo de produção econômico perverso e que deve ser abolido (RUSCHE; KIRCHHEIMER, 2004; FOUCAULT, 1991).

Todavia, a pena restritiva de liberdade é a forma preferida de punição dos sistemas jurídicos contemporâneos, dos operadores jurídicos e das pessoas em geral. Surgiu no século XVIII, consolidou-se no XIX e vem sendo criticada desde o tempo dos reformadores (BECCARIA, 1983; BENTHAM, s. d.; HOWARD, s. d.). Perdura e prolifera. Em países desenvolvidos, mostra-se conforme à garantia mínima da dignidade da pessoa humana; em países pobres, permanece medieval, caracterizando-se por distribuir miséria e ignomínia.

Nesse quadro, o sistema penitenciário brasileiro vive em caos. Desde o massacre do Carandiru, em 1992, quando 111 presos morreram, chacinas são comuns. Em 2017, em três eventos (no Complexo Penitenciário Anísio Jobim, no Amazonas; na Penitenciária Agrícola de Monte Cristo, em Roraima; e na Penitenciária de Alcaçuz, no Rio Grande do Norte), contabilizam-se 118 detentos mortos. Em 2019, em uma única rebelião, no Centro de Recuperação Regional de Altamira, no Pará, morreram 62 pessoas.

A atuação das autoridades competentes mostra-se insuficiente perante a gravidade da situação. Machado e Sloniak (2015, p. 215) revelam que juízes e promotores entendem que "a responsabilidade pelo descumprimento do comando legal não lhes é atribuível. Decorre de escolhas políticas, pois depende de investimentos"; sucedem-se Comissões Parlamentares de Inquérito no Congresso Nacional (quatro, nos anos de 1976, 1993, 2008 e 2015) e denúncias (cinco) à Corte Interamericana de Direitos Humanos, relacionadas a presídios brasileiros. Enada se altera.

Em decorrência disso, não estranha que a Igreja Católica esteja também atenta a essa situação. Desde a década de 1960, ela realiza, por meio das Irmãs do Bom Pastor, visitas a cadeias e penitenciárias (femininas) (PASTORAL CARCERÁRIA, 2019a). ${ }^{1}$ Nos anos 1970, percebem-se religiosos que promovem reuniões, cursos e celebrações

1 Há notícias ainda anteriores da participação da Igreja Católica. Em Porto Alegre, em 1949, as Irmãs inauguram um "Reformatório de Mulheres Criminosas", hoje administrado pelo estado gaúcho e chamado de Penitenciária Feminina Madre Pelletier (RIO GRANDE DO SUL, s. d.). 
litúrgicas sobre presídios, e visitas a eles. O trabalho se prolonga, e, no ano de 1986, acontece a primeira reunião nacional da Pastoral Carcerária, como serviço da Conferência Nacional dos Bispos do Brasil (CNBB).

Em 1997, a CNBB lançou Campanha da Fraternidade com o tema: “A fraternidade e os encarcerados” (CONFERENCIA NACIONAL DOS BISPOS DO BRASIL, 1997). Seu objetivo geral era

Despertar a sensibilidade e solidariedade dos cristãos, e de todos os homens e mulheres de boa vontade, para com as vítimas e para com os encarcerados, ajudando-os a perceberem a realidade carcerária do Brasil e a se comprometerem na realização das mudanças necessárias [...].

Outro grupo católico igualmente começa a atuar no sistema penitenciário, na década de 1970. Ele se apresenta como Associação de Proteção e Assistência ao Condenado (Apac), também acrônimo para “Amando o Próximo Amarás a Cristo”. O objetivo deste artigo é analisar o método Apac, apresentado como um modelo de prisão moderno.

A análise acontece a partir de documentos da Fraternidade Brasileira de Assistência aos Condenados (Fbac) e de estudos acadêmicos, comparando as formas de atuação. Preocupa-se, pois, em apresentar os discursos pertinentes ao método Apac, de "salvação" dos presos e do sistema penitenciário e da Pastoral, e da CNBB, de denúncia do sistema.

Este texto se justifica pelo fato de o modelo dito “apaquiano" apresentar-se como uma alternativa humana para a melhora e humanização da realidade prisional brasileira contemporânea. $\mathrm{O}$ modelo vem obtendo, em vários estados brasileiros, apoio de Tribunais de Justiça e do Ministério Público, e se organizam diversos grupos, formados por assistentes sociais, psicólogos, educadores e advogados, para implementá-lo. Tornou-se, então, agente no campo da política penitenciária pátria.

Cabe, pois, analisá-lo, situá-lo, histórica e ideologicamente, para verificar se, de fato, está promovendo a defesa dos direitos humanos dos presos. Assim, com fundamento nas lições de Michel Foucault, utilizando-se o método dialético, ${ }^{2}$ pretende-se desvelar a realidade do método Apac. Intenta-se conhecer os sites da Pastoral e da Fbac e cotejar os regulamentos disciplinares da Apac, de 2014 e 2015.

\footnotetext{
2 “O projeto dialético de visar o concreto passa pela prática científica, que é apenas uma prática social particular. A ligação entre teoria e prática é primordial, pois, se o método dialético se esforça por descobrir eventuais contradições nos próprios fatos que ele estuda, é na prática da própria dialética que será necessário procurar o critério da verdade científica" (BRUYNE; HERMAN; SCHOUTHEETE, 1991, p. 72).
} 
Busca-se, igualmente, perceber como estudos universitários observam o fenômeno. Para tanto, realiza-se pesquisa no catálogo de teses e dissertações da Coordenação de Aperfeiçoamento de Pessoal de Nível Superior (Capes), ${ }^{3}$ no qual, com a utilização da sigla Apac, surgem 143 referências. Todavia, 69 devem ser descartadas por se referirem à “autorização de procedimento de alta complexidade” (na área da saúde) ou à “área de proteção de ambiente cultural” (antropologia), entre outros. Restam 74 trabalhos sobre a Apac ou realizadas nela, fruto de mestrados acadêmicos e profissionais e teses de doutorado em áreas diversas (desde a teologia, a psicologia e a educação até o direito, a segurança pública e a arquitetura).

\section{O método Apac}

No meio do caos penitenciário, diz-se que surge um modelo de prisão diferente dos anteriores, vinculado à Apac, uma entidade civil de direito privado, sem fins lucrativos e com propósito de recuperar e reintegrar pessoas condenadas. São penitenciárias que recebem doações e verbas estatais para ressocializar até $85 \%$ dos seus "recuperandos". A Apac surge em 1972, na cidade de São José dos Campos, em São Paulo, pela iniciativa de um grupo liderado por Mário Ottoboni, advogado e jornalista. Eles pretendiam “evangelizar e dar apoio moral aos presos" (FRATERNIDADE BRASILEIRA DE ASSISTÊNCIA AOS CONDENADOS, 2019a) e "matar o criminoso e salvar o homem" (D’URSO, 1999, p. 96).

O modelo foi abandonado em São Paulo e migrou para Minas Gerais. Em 2001, é “adotado" pelo Tribunal de Justiça de Minas Gerais para se tornar modelo de política pública estadual (VARGAS, 2011, p. 62) e, hoje, conta também com o apoio da Fiat, do Ministério Público de Minas e do governo do Maranhão(FRATERNIDADE BRASILEIRA DE ASSISTÊNCIA AOS CONDENADOS, 2019a).

Silva Junior (2013, p. 40) revela que a sigla Apac pode ser lida de três maneiras: “Associação de Proteção e Assistência Carcerária”, “Associação de Proteção e Assistência aos Condenados" e "Amando o Próximo, Amarás a Cristo”. A religião não está apenas no acrônimo: o método surge a partir de "Cursilhos de Cristandade", avessos à Teologia da Libertação, e pretende

3 Informações disponíveis em: https://catalogodeteses.capes.gov.br/catalogo-teses/\#!/. 
[...] auxiliar a Justiça na execução da pena, recuperando o preso, protegendo a sociedade, socorrendo as vítimas e promovendo a Justiça restaurativa. [...] Ela ainda opera como entidade auxiliar do poder Judiciário e Executivo, respectivamente, na execução penal e na administração do cumprimento das penas privativas de liberdade (SILVA JUNIOR, 2013, p. 40).

A Apac busca humanizar as prisões, admitindo a função punitiva da pena (FRATERNIDADE BRASILEIRA DEASSISTÊNCIA AOS CONDENADOS, 2019a), eis que o método considera a sociedade justa, e “Assim, como as normas vigentes são, em essência, boas, cabe à APAC, evangelizando o preso, restaurá-lo moralmente, a fim de que este não venha mais a infringi-las” (SILVA JUNIOR, 2013, p. 37).

Silva Junior (2013, p. 42) destaca também:

Desta feita, a perspectiva moralizante da APAC nos parece cristalina. O preso-pecador, deve se emendar, corrigir suas condutas, a fim de que retorne recuperado para o convívio social. A sociedade, assim, ao menos em princípio, é boa e adequada. Aliás, mesmo o eufemismo pelo qual o preso é tratado - recuperando - já traz em si uma carga moral.

Para cumprir seus objetivos, o método possui 12 elementos essenciais: 1. participação da comunidade; 2 . recuperando ajudando recuperando; 3. trabalho; 4. espiritualidade; 5. assistência jurídica; 6. assistência à saúde; 7. valorização humana; 8. família; 9. voluntários; 10. Centro de Reintegração Social (CRS); 11. mérito; e 12. Jornada de Libertação com Cristo.

Da listagem desses elementos, percebe-se a relevância da experiência religiosa e se confirma um regresso às ideias dos já citados reformadores. A Apac "retoma, assim, as primeiras ideias de uma ‘humanização’ das penas” (RESENDE, 2013, p. 73).

Os documentos oficiais repetem, várias vezes, que a Apac recebe todos os presos, não havendo requisitos ou condições para o ingresso. Vargas $(2011$, p. 152) confirma que não importa o tipo de crime ou o tempo de condenação. Todavia, o preso precisa ter familiares residindo na comarca, apresentar bom comportamento e, em especial, passar por entrevistas nas quais se deve comprometer a aderir às regras do método. Santos (2017, p. 83) revela que o método prefere, inclusive, pessoas com penas mais longas:

[...] podemos supor que selecionar pessoas mais velhas para cumprir pena nas prisões apaqueanas tende a puxar para baixo a taxa de reincidência, uma vez que as pessoas na faixa etária entre 35 e 60 anos correspondem a aproximadamente $24 \%$ entre os reincidentes (BRASIL, 2015). 
Outro ponto de destaque no método se refere ao uso da religião como forma de ressocialização. O método pretende aprimorar a espiritualidade do indivíduo e, apesar de dubiedades no discurso, adota a fé cristã, impondo como um elemento essencial a participação na “Jornada de Libertação com Cristo”. Ottoboni e Ferreira (2004, p. 31) revelam que

A Jornada de Libertação com Cristo é, incontestavelmente, o ponto alto, o ápice do Método APAC. Aliás, não se deve falar em Método APAC sem a aplicação deste complemento fundamental, porque ele estabelece o marco divisor, o antes e o depois, na vida do jornadeiro.

Silva Junior (2013, p. 114) alerta que, mesmo com uma abertura ao pluralismo religioso, a assistência religiosa limita-se à prestada para católicos e evangélicos. A atuação de espíritas, quando permitida, ocorre de forma velada, e persistem alusões negativas a outras, como a muçulmana. Silva Junior (2013, p. 109) ainda destaca que um representante da Prision Fellowship International assegura acompanhar o método há 20 anos (em Itaúna, em Minas Gerais) e nunca ter visto o discurso de integração inter-religioso tornar-se realidade.

Em relação à religião, deve-se ainda destacar o "Programa A Viagem do Prisioneiro”, um estudo bíblico ecumênico, mas cristão (eis que baseado no Evangelho de Marcos e que pergunta: “Quem é Jesus?”, “Por que Ele veio?” e “O que significa segui-lo?”). O curso estimula "os participantes a se tornarem verdadeiros e fiéis seguidores de Cristo, colocando todo o aprendizado desde já em prática” (FRATERNIDADE BRASILEIRA DEASSISTENNCIA AOS CONDENADOS, 2019b).

No que se refere a documentos, o Regulamento Disciplinar das Apacs foi aprovado em 6 de abril de 2015 e está disponível no site, assinado pela Fbac, pelo Tribunal de Justiça do Estado de Minas Gerais, pelo Ministério Público do Estado de Minas Gerais, entre outros. Esse regulamento é bem mais sintético do que o anterior, está composto por 40 artigos e se divide em considerações iniciais e mais cinco capítulo, quais sejam: dos direitos, obrigações e deveres dos recuperandos, das faltas e das sanções disciplinares, das recompensas e regalias/do elogio e do recuperando modelo, dos jogos, apostas e negócios, e disposições finais.

Na versão anterior, de março de 2014, eram 22 capítulos, com 106 artigos. Seus títulos mostravam com mais detalhes os tópicos relevantes do método no dia a dia: da assistência ao recuperando, dos direitos, obrigações e deveres dos recuperandos, 
das faltas e das sanções disciplinares, do elogio e do recuperando modelo, do Conselho de Sinceridade e Solidariedade, da assistência aos alcoólatras e toxicômanos, das cantinas, prestações de conta e contribuições, dos jogos, apostas e negócios, do uso da televisão, do uso do telefone, dos doentes e da assistência médica, dos porteiros e auxiliares de plantão, da higiene pessoal e faxina, da secagem de roupas e das plantas, das celas e dormitórios, das solicitações de transferência de recuperandos, do trabalho do recuperando, regime fechado, regime semiaberto, regimes aberto e semiaberto autorizados ao trabalho externo, das visitas dos familiares dos recuperandos e das disposições finais.

Desde as considerações iniciais do regulamento, aprende-se o seguinte: "jamais olvidando que os recuperandos das APACs são condenados da justiça e que os Centros de Reintegração Social são unidades prisionais”, e se garante a ortodoxia: “As normas comuns a todas as APACs não poderão ser alteradas, a não ser que haja expressa autorização da FBAC - Fraternidade Brasileira de Assistência aos Condenados [...]”.

O método quer promover a ressocialização e, para tanto, propõe uma prisão "humanizada", sem superlotação, e oferece aos “recuperandos”, além dos direitos previstos no Código Penal brasileiro e na Lei de Execução Penal (LEP), conforme o artigo $1^{\circ}$ do Regulamento Disciplinar, entre outros, atendimento pelo diretor do estabelecimento e "Igualdade de tratamento salvo quanto às exigências da individualização da pena [...]". Garante ainda chamamento nominal e

Leitura de todos os órgãos da imprensa, tais como jornais, revistas e demais periódicos, editados no país, em língua portuguesa, desde que não contenham incitamento à violência, à subversão da ordem ou preconceito de religião, raça ou classe social e não comprometam a moral e os bons costumes [...] (artigo $1^{\circ}$, VI).

Contudo, o regulamento aponta obrigações e deveres (artigo $2^{\circ}$ ), como “Comportamento disciplinado e cumprimento fiel da sentença", "Obediência ao servidor e respeito a qualquer pessoa com quem deva relacionar-se”, submissão à revista pessoal, arrumar a cama, não possuir publicações pornográficas, cumprir horários (das refeições, alvoradas e atos socializadores) e evitar “palavrões”. Além disso, é “proibido participar de manifestações e/ou tumulto coletivo, que ameacem a segurança e a disciplina”, apostas de jogos e assobios ou ruídos que prejudiquem a vigilância e a disciplina. 
O descumprimento dos deveres e das obrigações gera penalidades. São faltas leves (artigo 15), entre outras, falar com visitantes sem autorização ou usar bermuda, boné e camiseta regata na presença de visitantes e voluntários. Entre as médias (artigo 16), destaca-se possuir ou utilizar “máquinas” de tatuagem. Entre as graves (artigo 17), destacam-se as seguintes: fugir, usar a cela para visita íntima ou familiar, ou praticar conjunção carnal com pessoas do mesmo ou de outro sexo.

O banho diário é obrigatório, prescrevendo ainda o artigo $1^{\circ}$, XXIII, que o "recuperando" esteja barbeado e com os cabelos cortados (sendo proibido corte de cabelo com máquina zero) (artigo 57).

Não há menção a homossexuais ou à exclusão deles, mas o antigo regulamento utilizava sempre os termos no feminino, e, no Infopen, informa-se que nenhuma unidade da Apac possui espaço para população LGBT. Mesmo atualizado, o regimento ainda prevê que os recuperandos devam ser sinceros e honestos e evitar a companhia de mulheres "de vida fácil" ou de "conduta suspeita”.

O novo regulamento é econômico ao definir o cotidiano da Apac, mas um anexo ("Das celas e dormitórios") declara que se deve "Manter o horário de silêncio (22:00) e da alvorada (06:00)”. O antigo previa mesmo horário, definindo que as atividades se iniciavam com prática religiosa seguida de deslocamento para o trabalho.

O regulamento revela a participação em concursos e eleições para escolha da melhor cela e do melhor reeducando. Os vencedores são aclamados, e os perdedores podem ser obrigados a acolher em sua cela um troféu "porquinho", como forma de incentivo para melhorarem.

A penalidade mais grave a ser aplicada para as faltas está prevista no artigo $5^{\circ}, \mathrm{VI}$, e refere-se à transferência e ao retorno para o sistema penitenciário comum.

A leitura dos instrumentos muito revela sobre o método. Ainda que esteja sendo alterado para diminuir o moralismo, permanece sendo exemplo perfeito dos ensinamentos de Foucault. O disciplinamento verificado na Apac suplanta o castigo corporal, impondo adestramento que transforma o ser humano em um mero corpo útil. Mais do que isso, perpetua efeitos do sistema prisional no detento: infantiliza o ser humano, reduz sua autodeterminação, despoja-o de sua masculinidade, empobrece e envilece (FEAUX, 1991, p. 673; FRAGOSO, 1980, p. 763; THOMPSON, 1993, p. 58; PIMENTEL, 1989, p. 76).

Para prosseguir, deve-se conhecer outro discurso católico sobre o mesmo tema. 


\section{A Pastoral Carcerária}

Importante documento da Igreja Católica brasileira sobre a questão prisional foi publicado quando da Campanha da Fraternidade, promovida pela CNBB, no ano de 1997: A fraternidade e os encarcerados: Cristo liberta de todas as prisóes. Esse documento faz os seguintes questionamentos:

O problema levanta muitas perguntas sobre os encarcerados. Não foram eles próprios que construíram esta situação? Por que compadecer-se deles, se eles não tiveram compaixão? Por que interessar-se por seus direitos, se eles não respeitaram os direitos dos outros? Outras perguntas questionam a administração de justiça: Como é complicada? Por que há tanta impunidade? São essas as únicas pessoas que merecem estar na prisão? Há também muitos questionamentos sobre a atuação de policiais, o atendimento aos presos e às presas, o trabalho dos agentes penitenciários. São perguntas que todos podem levantar. Mas cada um e toda a sociedade deve questionar-se frente à realidade dos encarcerados (CONFERÊNCIA NACIONAL DOS BISPOS DO BRASIL, 1997, p. 48).

Para resolvê-las, busca resposta não em leis preconcebidas como justas, mas na análise da sociedade. E a Conferência Nacional dos Bispos do Brasil (1997, p. 91) entende que, no Brasil contemporâneo, existem classes sociais diversas em um ambiente de valorização do ter, no qual "O consumismo vem associado a uma desvalorização do trabalho". Nessa situação, o salário do trabalhador "compra (quando compra!) apenas a sobrevivência”. Assim:

Nem sempre um ato objetivamente mau provém de pessoa que consciente e deliberadamente optou pelo erro. Existe além do ato praticado, a própria situação concreta do transgressor, com todas as suas circunstâncias: carências, marginalização, desemprego, tipo de educação, abandono etc. O livre arbítrio é condição indispensável e inegável de nosso comportamento humano, mesmo se reconhecemos que ele se exerce dentro de uma faixa limitada pela situação e os condicionamentos que cada um vive. A faixa da livre decisão varia bastante de pessoa para pessoa (CONFERÊNCIA NACIONAL DOS BISPOS DO BRASIL, 1997, p. 101).

Logo, praticado o crime, a violência, deve-se seguir a lição de Jesus: aplicar amor, bondade e perdão para corrigir o erro, pois "toda pessoa é maior que sua culpa [...]" 
(CONFERENCIA NACIONAL DOS BISPOS DO BRASIL, 1997, p. 18). Portanto, se o perdão precisar ser acompanhado de pena, que ela seja justa e a pessoa receba tratamento sem excessos ou maus-tratos, em ambiente digno(CONFERENCIA NACIONAL DOS BISPOS DO BRASIL, 1997, p. 29).

A página da CNBB não faz menção às Apacs, mas sim à Pastoral Carcerária. Em 31 de julho de 2019, divulgava "Nota da Pastoral Carcerária Nacional sobre o massacre em Altamira”. Ela informa:

Diante de mais um episódio de mortes no sistema carcerário, ocorrido dois meses após os massacres em Manaus, a Pastoral Carcerária Nacional vem a público se posicionar e afirmar, mais uma vez, que esses episódios de mortes massivas não são casos isolados: são consequências diretas do funcionamento do sistema prisional (CONFERÊNCIA NACIONAL DOS BISPOS DO BRASIL, 2019b).

E, em página dedicada às atividades das pastorais, a CNBB indica diversas notícias, entre as quais: “Após 10 dias de visita a Manaus, agentes da Pastoral Carcerária relatam situação”, "Pastoral Carcerária repudia alterações em leis anunciadas pelo ministro da Justiça”, "Brasil está na contramão da redução da população carcerária aponta Pastoral Carcerária” (CONFERÊNCIA NACIONAL DOS BISPOS DO BRASIL, 2019c).

A leitura torna evidente que a $\mathrm{CNBB}$ observa a questão penitenciaria de forma sistêmica e política, em conjunto com a Pastoral. Há compreensão de que não se trata somente de punir um ato delituoso praticado de forma individual por um ser humano, mas também de pensar que o crime acontece em sociedade e todos (indivíduo, sociedade e Estado) possuem responsabilidade. Também se percebe, desde logo, um viés que aponta para a ineficácia da pena restritiva de liberdade, que isola a pessoa sem respeito à sua condição humana. É uma outra concepção sobre a punição.

Ela se aprofunda quando se observa o site institucional da Pastoral Carcerária. ${ }^{4}$ Nele, os principais temas são a formação de uma "agenda nacional pelo desencarceramento", o "combate e prevenção à tortura”, a condição da "mulher encarcerada”, a opção pela "justiça restaurativa” e a atuação da "Igreja em saída na luta contra o cárcere”.

4 Disponivel em: https://carceraria.org.br/. 
Dois tópicos, pois, pela extinção da prisão. A agenda iniciou suas atividades em 2013 e continua ativa. Em 2017, promove o II Encontro Nacional pelo Desencarceramento e conta com apoio de mais de 40 organizações (PASTORAL CARCERÁRIA, 2019b). No mesmo sentido, baseando-se em palavras do papa Francisco, declara:

Nós da Pastoral Carcerária sabemos bem que nosso horizonte é sermos parte dessa Igreja "em saída”, na luta cotidiana contra o cárcere. [...] Sendo assim, a Pastoral Carcerária, hoje, dentro de uma Igreja “em saída”, tem uma única e irrenunciável expressão: o mundo sem cárceres (PASTORAL CARCERÁRIA, 2019c).

Para se perceber o ideário da Pastoral Carcerária, pode-se refletir sobre os escritos no que tange à aplicação da justiça restaurativa. Neles, há declaração explícita de que "Esse sistema punitivo cria um ciclo de violência, sem que vítima ou ofensor tenham a possibilidade de se recuperar", e propõe, para romper o ciclo, o uso não de uma prisão "melhor", mas da justiça restaurativa (PASTORAL CARCERÁRIA, 2019d).

Presente em todos os estados do país, a Pastoral busca atuar na realidade do sistema prisional de forma cotidiana: "ser a presença de Cristo e de sua Igreja no mundo dos cárceres, caracterizado pela superlotação, condições insalubres e tortura sofrida pelas pessoas privadas de liberdade [...]". Promove, para tanto, escuta e acolhimento, anuncia a "Boa-Nova", enfrenta o desrespeito e as violações de direitos humanos, denuncia que prender mais pessoas (na maioria pobres e negras) não diminui a violência e que o encarceramento "serve para torturar as pessoas mais pobres e gerar ainda mais violência" (PASTORAL CARCERÁRIA, 2019e).

Ela possui como objetivos estar junto das pessoas privadas de liberdade, buscar a libertação integral, lutar contra todas as leis e normas que se opõem à dignidade e aos direitos fundamentais das pessoas privadas de liberdade e/ou que dificultam o exercício da liberdade religiosa em benefício dos reclusos e respeitar a dignidade da pessoa humana (PASTORAL CARCERÁRIA, 2019e).

Para tanto, propõe, entre outras, a descriminalização de condutas, em especial aquelas relacionadas à política de drogas, suspensão da construção de novas unidades prisionais, limitação das prisões cautelares, redução de penas e proibição da privatização do sistema prisional (PASTORAL CARCERÁRIA, 2019e). 


\section{Foucault e direitos humanos}

A Apac oferece, a quem aceitar se submeter ao método, condições dignas de hospedagem, previstas na LEP. Mas as informações apresentadas mostram que não se trata nem mesmo de uma proposta reformista. Aparentemente, é um método “bom”, em conformidade com os direitos humanos. Entretanto, oculta imposições e controle total sobre a vida do recuperando. Resende (2013, p. 89) alerta: "Mesmo considerando os avanços que o método traz não devemos nos conformar com essa alternativa, pois também reconhecemos seus limites e contradições”.

Para quem o defende, pessoas preocupadas com a situação do sistema penitenciário, trata-se de fazer o bem, ainda que em escala limitada, dentro de uma missão. O discurso das Apacs, de amor e redenção, atrai, e os voluntários explicam sua participação a partir de relatos orais que demonstram a importância de realizar algo; também dizem que os críticos do sistema prisional nada realizam, somente falam mal. Mayrink (2018, p. 25) escreve:

Durante a graduação em Direito, revelaram-se a vocação acadêmica e o interesse pelas causas sociais que envolvem a defesa e a promoção dos Direitos Humanos. Imediatamente após a colação de grau, no ano 2000, foi fundada a organização eleita por mim como espaço de realização profissional. [...] Após 15 anos de funcionamento, a instituição, que desde 2000 tem sido ininterruptamente um espaço de realização de pessoas e de aprimoramento profissional por intermédio da presidência que com muita honra ocupo, cresceu e se consolidou.

Ela, inclusive, defende que Foucault "amaria” as Apacs, afirmando tratar-se de uma "neoprisão".

[...] Foucault não conheceu enquanto sujeito autor a realidade APAC. Ele teve contato com prisões em que o vigia era alguém que não era preso. Uma prisão em que eram necessárias restrição física à mobilidade, algemas, segurança, estrutura física panóptica com visibilidade axial absoluta e incomunicabilidade lateral controlada. A prisão que analiso aqui é uma prisão que não mantém qualquer ligação com a estrutura arquitetônica de um átrio com vigilância ostensiva centralizada, com corredores sobrepostos de forma que o vigia do andar superior possa enxergar o andar posterior. A prisão APAC não usa algemas, cães, concertinas nos muros. Trata-se, portanto, de uma prisão nova (MAYRINK, 2018, p. 141). 
Parece que Mayrink (2018) desconhece o fato de que a tecnologia transformou o vigiar, que agora é eletrônico, não mais arquitetônico, embora permaneça disciplinar. Assim, o regulamento das Apacs prevê como infração (artigo 24, incisos IV e XX, e artigo 25, XII) faltar com a verdade e não ser disciplinado, não cumprir "fielmente" a sentença e "Ser omisso aos movimentos individuais ou coletivos de fuga ou de subversão à ordem ou à disciplina”. No anexo III, consta o seguinte no "Termo de adesão": "após tomar conhecimento da existência de um PACTO entre os recuperandos [...], que diz que falar a verdade não será considerado como ‘caguetagem' na APAC, [...] comprometendo-me [...] [a] vigiar diariamente para que não entre drogas na APAC”. Então, “caguetar”, por força normativa interna, na Apac não é o denunciar alguém culpado de algo - um claro exemplo de "novilíngua” (ORWELL, 2004).

Mas, mesmo um reformador como Beccaria (1983, p. 41), que não consegue se definir pela possibilidade ou não da delação, ressalta que essa ação "não está livre de perigos, pois a sociedade assim autoriza a traição, que não agrada aos próprios celerados”.

A vigilância, pois, está muito mais presente do que em um modelo arquitetônico ou eletrônico. O modelo instaura a obrigação de seguir as regras pelo medo de ser denunciado pelo colega, termina com a fraternidade entre os iguais e os transforma em instrumento de controle da direção da instituição.

Parece Mayrink (2018) desconhecer que a análise principal de Foucault se encontra nas técnicas de poder e que na Apac se potencializa o controle do agir e pensar do indivíduo. Parece desconhecer que o mestre francês não se preocupa tão somente com a degradação do sistema prisional; que equivale a prisão, como técnica de poder com a escola, à oficina e ao quartel, por buscar o adestramento do ser humano. A prisão serve para a transformação técnica dos indivíduos (FOUCAULT, 1991, p. 208-209).

A “disciplina” não pode se identificar com uma instituição nem com um aparelho; ela é um tipo de poder, uma modalidade para exercê-lo, que comporta todo um conjunto de instrumentos, de técnicas, de procedimentos, de níveis de aplicação, de alvos; ela é uma "física” ou uma "anatomia” do poder, uma tecnologia. E pode ficar a cargo [...] de aparelhos estatais que têm por função não exclusiva mas principalmente fazer reinar a disciplina na escala de uma sociedade (a polícia) (FOUCAULT, 1991, p. 189).

Silva (2014, p. 65) também esclarece: 
A característica fundamental do modelo APAC, partindo do pressuposto de prisão aberta, onde não há vigilância ortodoxa (grades, muros, vigias, sentinelas, guardas, policiais), não rompe com a compreensão da passagem de rito descrita por Foucault (2010) ao descortinar o nascimento da prisão.

Em decorrência disso, Boullant (2003, p. 98) revela que Foucault

[...] mostra que a prisão é uma instituição violenta que só pode gerar violência. [...] Foucault denomina a "estratégia do poder": assustar enquanto finge assegurar a defesa da sociedade. [...] A prevenção de Foucault em relação a qualquer política de prevenção teria raízes aqui.

Logo, premonitoriamente, pode-se dizer com mais lógica que, se analisasse essa prisão, mais plausível do que considerar a "boa vontade" da Apac e dos apaquianos seria ele se lembrar do que escreveu:

A operação penitenciária, para ser uma verdadeira reeducação, deve totalizar a existência do delinquente, tornar a prisão uma espécie de teatro artificial e coercitivo onde é preciso refazê-la totalmente. $\mathrm{O}$ castigo legal se refere a um ato; a técnica punitiva a uma vida [...] (FOUCAULT, 1991, p. 223).

A crítica de Foucault vai além da prisão, ela se manifesta contra uma forma de dominação, de poder, de submissão do indivíduo. E percebe-se ser justamente essa a estratégia do método Apac para “ressocializar” o recuperando. O método incorpora uma técnica de poder que se estende para a vida do condenado, que o obriga a reconhecer o crime (sem refletir sobre as condições nas quais aconteceu) e aceitar a pena como justa; cria a obrigação de aceitar a palavra divina. O método impõe um modelo de punição total que exige submissão do corpo e da alma.

A tese de Mayrink (2018) incorre em erro criticado por Oliveira (2014) nos estudantes de direito: o professor destaca que eles citam autores sem conhecê-los. O exemplo que Oliveira (2014) utiliza está precisamente no citar frequente do mestre francês: "Foucault ironiza, para dizer o mínimo, o projeto ressocializador do direito penal moderno, com seu séquito de médicos, psicólogos, conselheiros espirituais etc. [...]”. Econclui que escrever, como o fazem os graduandos, em seus trabalhos de conclusão de curso, sobre ressocialização utilizando-se dele é impensável. 
Mas cabe ir mais longe sobre a situação do recuperando:

Assim, a prática religiosa colabora para permitir a atuação mais facilitada do poder pastoral. O poder pastoral assegura a salvação do recuperando na vida futura, ao sair do cárcere - a "vida no mundo". Cuidando de cada indivíduo em particular, o poder pastoral, sempre pronto a se sacrificar em benefício do rebanho e de cada ovelha, é exercido explorando as almas das pessoas, conhecendo seus detalhes mais íntimos e, com isso, dirigindo a consciência. (FOUCAULT, 2009, p. 237) (MAYRINK, 2018, p. 144).

Há de se esclarecer que a vida na prisão Apac acontece limitada não apenas pela proibição de ir e vir, mas também pela rotina rígida e opressora. A disciplina que adestra e faz do ser humano um mero corpo útil, retirando do ser a reflexividade e autonomia, mostra-se cruel como os castigos bárbaros do passado. A leitura de Foucault condena o método.

A percepção de que o processo disciplinador de Foucault parecia estar longe da realidade prisional pátria muda com a inauguração das Apacs (e do sistema penitenciário federal). A aproximação acontece, e se torna indispensável retomar os estudos do mestre francês nestes "tristes trópicos”.

Sobre a questão religiosa, Frei Beto $(2019$, p. 1) destaca que não se trata de condenar o método: "É uma exigência evangélica que a Igreja se preocupe com a situação dos presos [...] a APAC tem o mérito de existir e de procurar, a seu modo, reduzir o índice de reincidência criminal”. Porém, cumpre questionar se "a religião deve ser utilizada como disciplinadora arma ideológica”.

O método APAC parece-se a uma "laranja mecânica" onde o preso é minuciosamente programado, a ponto de não obter espírito crítico, critério base da liberdade da consciência. Formam-se seres “cristãos”, nos quais a religião é o carimbo da garantia da não reincidência. A cada "conversão", a sociedade livra-se de mais um marginal que poderia ameaçá-la. Não se pergunta como surgem os marginais e os criminosos. Não se buscam as causas e nem se denuncia a estrutura social que engendra, para a sua preservação, a existência do criminoso e do sistema penitenciário meramente punitivo (FREI BETO, 2019, p. 3).

Ele ainda critica a APAC pela rigorosa vigilância aplicada pelo método, por pregar que o homem deve se tornar exemplo de virtudes, por ignorar as causas da criminali- 
dade, por não questionar o papel de exemplo dos voluntários, adotando, assim, uma "pedagogia pastoral nitidamente colonialista”.

Destaque-se, do ponto de vista jurídico, ser a exigência de participação em culto religioso vedada pela LEP, artigo $24, \$ 2^{\circ}$ : “Nenhum preso ou internado poderá ser obrigado a participar de atividade religiosa”. Logo, condicionar a avaliação positiva do recuperando descumpre flagrantemente esse dispositivo, afinal, mesmo possuindo bom comportamento e cumpridos os requisitos da LEP, artigo 112, poderá não receber a progressão, pois ela depende igualmente da adesão ao método e da perseverança na fé.

Em relação ao sexo no âmbito prisional, cabe destacar que a obra clássica de BRITTO (1934, p. 128), conforme o pensamento do início do século XX, desvela que os presos submetidos à abstinência sexual ficariam expostos ao homossexualismo, como uma válvula de escape. E Clemmer (1966, p. 249) expõe que, na prisão, como em outras comunidades isoladas, é comum o desenvolvimento do que denomina “anormalidades sexuais”. Sykes (2007, p. 70), escrevendo nos anos 1950, revela que, “Ao contrário do preso em muitos países latino-americanos, o preso da prisão de segurança máxima em Nova Jersey não desfruta do privilégio das chamadas visitas conjugais [...]”. O sexo, pois, existe e sempre existiu no âmbito prisional. Aymard e Lhuilier (1997, p. 75), ao tratarem do sistema na França, apontam que as relações sexuais são proibidas, mas os agentes fazem "vistas grossas".

No método Apac, por evidente, em coerência com suas posturas morais, a sexualidade é controlada e auxilia a seletividade. Somente recebem visitas íntimas os presos “familiares”, ou seja, quem possui uma certidão de casamento ou união estável registrada em cartório. Essa seletividade obriga quem se une a outra pessoa de forma consensual, sem regularização, à abstinência, ao onanismo ou ao homossexualismo (proibido, pois é vedada a prática de sexo nas celas). Não há, todavia, como referido, uma proibiçãoa práticas homossexuais, “somente” não existe espaço para a população LGBT.

Assim, quando se analisa o trabalho das Apacs e da Pastoral Carcerária, distinguem-se claramente duas propostas de atuação: uma voltada a beneficiar alguns presos que aceitam se submeter ao "tratamento" (pena e regras morais) e outra crítica do sistema que denuncia a prisão massiva de pobres e negros, que se opõe à tortura e que luta contra o cárcere e sua violência.

Esta é outra questão relevante: os defensores do método não percebem que o sistema penitenciário possui por princípio básico o encarceramento, e este tem funções nada generosas. Não há como “ressocializar” isolando a pessoa da comunidade, tampouco 
reeducar num ambiente prisional draconiano por natureza. Nele a violência não é simbólica e sim explícita. O sistema penitenciário serve para segregar e desumanizar as pessoas. E a prisão Apac apenas complementa o sistema, não o transforma. E, como aponta a Pastoral, o sistema deve ser combatido, criticado, para que seja substituído por algo melhor. A sua reforma, parcial, serve tão somente para legitimá-lo.

Resende (2013, p. 88), nesse sentido, verifica a função do método em legitimar as prisões e nunca adotar um discurso favorável à desinstitucionalização prisional. Para tanto, utiliza uma fala sobre boas práticas, de parceria entre sociedade civil (Fbac) e Estado, para garantir a conversão, a recuperação e a ressocialização, o sucesso das políticas “Re”, preservando o discurso da punição e repressão.

Essa perspectiva está igualmente em Mayrink (2018, p. 141): “No entanto, ao contrário do nascimento da prisão, que extinguiu a execução pública de penas de morte, a APAC não extingue o sistema penitenciário tradicional”. Pelo contrário, ela confirma que a Apac necessita de um sistema prisional caótico para "ser objeto de desejo do preso, para que haja o ritual de passagem do inferno para a 'mãe' [...]" (MAYRINK, 2018, p. 141).

Em decorrência disso, não estranha que sua legitimidade seja questionada. As casas prisionais que utilizam o método Apac integram o sistema, e se alcançam bons resultados, e isso decorre de fatores "além daqueles que os seus gestores propagam" (SANTOS, 2017, p. 92):

Assim, podemos inferir que as APACs surgem nesse contexto, são atores importantes para o sistema penitenciário mineiro e, aparentemente, mantêm uma tradição histórica daquele Estado: mantêm uma lógica de seleção entre os presos que merecem a redenção em melhores prisões (se é que podemos fazer essa afirmação de que há "melhores prisões”) e aqueles outros que devem sofrer em prisões sem condições mínimas de subsistência. Neste sentido, parece-nos que o TJMG identificou a importância das APACs enquanto uma ferramenta útil no controle sobre as pessoas que cumprem pena de privação de liberdade no sistema prisional daquele Estado (SANTOS, 2017, p. 75).

Esse é “desvio" que se percebe em todas as “boas” prisões brasileiras. Esses modelos somente funcionam graças à existência de "infernos". Alguns presos preferem se submeter a um controle total, a uma disciplina exacerbada, para fugir da miséria humana decorrente da superlotação. 
Aliás, a superlotação aparece como a maior reclamação da massa carcerária, e ela potencializa as demais: a comida piora, a atuação dos agentes penitenciários e técnicos (advogados, psicólogos) é prejudicada, o lazer diminui, falta espaço para repouso, há maior disseminação das drogas. $O$ único fato de uma unidade Apac não aceitar mais presos do que sua capacidade, o que não pode acontecer no sistema comum, que recebe tantas pessoas quanto julgado necessário pelo sistema penal, basta para inviabilizar qualquer comparação.

Ainda assim, os defensores do método Apac o declaram uma forma de garantir a efetividade dos direitos humanos no sistema prisional. Entretanto, cabe ainda destacar o que são direitos humanos e como se deve garantir sua efetividade.

Parece evidente que hoje os mais diversos povos estão de acordo sobre sua importância para a humanidade e com a necessidade de sua proteção; não há país que deixe de afirmar respeito a eles e busque sua efetividade (BOBBIO, 1992). Há divergência, todavia, sobre a quais direitos eles se refiram, como devem ser interpretados e, em especial, como os Estados devem agir para garanti-los, efetivá-los. Essa perspectiva serve igualmente para entidades e pessoas. Todos afirmam a proteção dos direitos humanos.

Para compreender a relação dos discursos das Apacs e da Pastoral Carcerária, devem-se considerar os direitos humanos um ideal comum de povos e nações (Declaração de 1948), um sistema de valores, "produto de ação da coletividade humana” (SORONDO, 1991).

Eles são históricos (a própria existência de duas grandes declarações, uma datada do século XVIII e outra do XX, demonstra tal fato), e, como ressalta Bobbio (1992, p. 42), alguns desses direitos são absolutos (como a não escravidão e a não tortura) e outros relativos (a liberdade de expressão).

Sorondo (1991, p. 7) leciona que as funções dos direitos humanos são criticar a ordem existente e orientar a ordem jurídica para construir uma utopia: “os Direitos Humanos nunca podem ser alcançados totalmente. A luta por uma nova ordem, que transforma as condições históricas em que se origina, modifica em extensão e profundidade a consciência coletiva”. Nesse mesmo sentido Wolkmer (2017, p. 34) propõe pensar os direitos humanos como um "interregno conflitivo de lutas sociais para o relacionamento de uma vida com mais dignidade. [...]”.

Eis a polêmica em torno do método Apac: "Respeita ou não a dignidade da vida humana?” e "Respeita ou não os direitos humanos?”. O método Apac declara oferecer aos presos uma prisão que respeita os direitos humanos, resgata o discurso dos reformadores, 
da possibilidade de isolar de forma mais digna. Trata-se, pois, não de um método inovador, mas perpetuador que, desde 1972, propõe-se a moralizar o criminoso, “matá-lo", para fazer surgir o "homem bom".

A existência de um espaço próprio e apropriado para a execução penal e a obrigatoriedade do desenvolvimento de uma esfera espiritual/religiosa aparecem como elementos fundamentais no processo. Logo, “A metodologia APAC utiliza um critério utilitarista que está impregnado no panoptismo. Tudo deve servir e ter proveito, em direção à maximização da experiência com Deus” (SILVA, 2014, p. 58).

No processo, há indícios de humanização: chamamento nominal, direito à informação, possibilidade de contato telefônico com parentes, liberdade de culto. Mas são diversos os deveres para usufruir das benesses que são sempre vigiadas.

Importa comparar o método Apac com o conceito de "prisionização" desenvolvido por Clemmer (1966). Essa ideia se refere ao grau de assimilação do ser humano dentro do sistema prisional e aparece como algo que facilita a vida da pessoa privada de liberdade durante a pena, mas prejudica sua afirmação como ser autônomo, com vínculos com a sociedade extramuros.

No método Apac, verifica-se, integram-se presos que estão menos propensos à prisionização. Entre eles, destacam-se os indivíduos com maior estabilidade da personalidade, recusa de integração do sistema, disposição de colaborar com o sistema e manutenção de relacionamentos positivos dentro e fora dos muros da prisão. Todas essas características podem ser percebidas em quem aceita e se voluntaria para se submeter ao método. Contudo, pelas características do método, os presos serão mais prisionizados por terem penas maiores.

Sykes, ao escrever na década de 1950, não priorizou o potencial de violência dos prisioneiros, estava mais preocupado com a capacidade muito maior de repressão por parte do Estado. Escrevendo à sombra de Nuremberg e da Guerra Fria, Sykes sabia que o fantasma do totalitarismo não estava muito longe. As dores da prisão, observou ele, aniquilam a pessoa, dissolvendo a individualidade e a autonomia. Em sua fase repressiva, a prisão exige responsabilidade. [...] Sykes coloca o paradoxo básico da prisão melhor que a maioria: não é possível promover o livre arbítrio - agindo com autocontrole e previsão - extinguindo-o. [...] (WESTERN, 2007, p. XXIV).

Cabe ainda ressaltar e comparar a diferença de perspectivas entre o método Apac e as propostas da CNBB e da Pastoral Carcerária. Essas últimas se dedicam não apenas 
a acolher os presos, mas igualmente a refletir sobre o sistema que os define como criminosos e os encarcera, bem como valorizam o livre-arbítrio. Elas propõem a utopia, a superação do sistema prisional, a substituição por um método que reconcilie os seres humanos com eles próprios e seus semelhantes.

Se os direitos humanos são a busca crítica da utopia, o método Apac é o regresso ao pensamento reformador do século XVIII. Ele deve ser criticado por desumanizar os seres humanos e impor a "salvação" da alma como alternativa ao caótico sistema prisional brasileiro. O respeito pelos direitos humanos não se resume a oferecer uma cama limpa e um prédio asseado; importa também respeitar a pessoa como sujeito. Não basta oferecer uma área de lazer sem excrementos, mas necessita também permitir o livre desenvolvimento do ser humano, sem imposições sobre como deve ser ou pensar. No âmbito do sistema carcerário, a defesa dos direitos humanos significa não lutar por prisões “melhores”, mas por um mundo sem prisões, pela libertação de todas as prisões.

\section{Conclusão}

Este artigo teve como objetivo analisar o método Apac. O método dialético serviu para buscar contradições a fim de compreender aspectos relacionados ao respeito aos direitos humanos dos presos. Houve análise de documentos da Fbac e de teses e dissertações elaborados sobre o método, que foram cotejados com dados de outra intervenção (Pastoral Carcerária) da Igreja Católica no sistema prisional. Como referencial teórico, adotaram-se as lições de Michel Foucault.

Assim, conclui-se que o método Apac propõe uma prisão nova e diferente. Acredita que o preso, pecador, pode e deve ser recuperado. Existem critérios para ingresso nas prisões que adotam o método, como ter bom comportamento e se comprometer, voluntariamente, a aderir ao método. A importância da religião (cristã) no método é enorme, bem como da disciplina. A ideia é de que os recuperandos se tornem humanos bons, sinceros, honestos.

A Pastoral Carcerária, com apoio da CNBB, propõe uma intervenção diversa. Ela crítica o sistema econômico e prisional e considera que a capacidade de livre-arbítrio varia entre pessoas de classes sociais diferentes. Assim, se há crime e deve haver pena, acompanhada de perdão, preconiza que ela seja justa, cumprida em um ambiente digno, sem excessos ou maus-tratos. 
O discurso critica o aumento da população carcerária e a ineficácia da pena restritiva de liberdade. Fala da necessidade de pensar o desencarceramento, prevenir a tortura e implantar a justiça restaurativa, detalhando sobre a importância de descriminalização de condutas relacionadas à política de drogas e suspensão da construção de novas penitenciárias. Preconiza liberdade religiosa para as pessoas presas, bem como garantias para que tenham uma vida digna.

Percebe-se que são duas formas diametralmente opostas de encarar o caos prisional e a sociedade pátria. Uma propõe hospitalidade digna com controle total sobre a vida do recuperando, impõe vigilância disciplinar. Técnicas de poder do sistema prisional se potencializam com a utilização do método que prega o controle do agir e pensar do indivíduo, totalizando a existência do “delinquente”, buscando sua transformação.

O modelo Apac não é novo; representa uma prisão não superlotada, com educação religiosa. E se enquadra perfeitamente nos tipos abordados por Foucault, para quem a punição total, a submissão do corpo e da alma, mostra-se indesejável.

A crítica ao modelo se expande. Essa prisão serve apenas de complemento ao sistema; agrega qualidade de vida a quem se submete. Em especial, ela serve para legitimar o sistema, não para melhorá-lo.

Por sua vez, a CNBB e a Pastoral Carcerária refletem sobre o sistema que estigmatiza os presos e os encarcera. Elas refletem sobre os condicionamentos existentes e valorizam o livre-arbítrio que deve resultar em escolhas pautadas na liberdade e não na ameaça de sofrer um castigo pior. Entendem que a aproximação do ser humano com a religião deve ser livre e não uma “arma ideológica” ou condicionante para obtenção de dignidade.

Elas buscam os direitos humanos como sociedade justa. Seu discurso é o da luta por um mundo melhor, para todos. Afinal, os direitos humanos não se resumem a um prédio pintado, a uma cama e a banheiros limpos. Importa perceber o ser humano como sujeito livre, para ir e vir, para pensar e agir.

No que tange à defesa dos direitos humanos no âmbito penitenciário, deve-se não apenas lutar por prisões "melhores", mas por um mundo sem prisões, pela libertação de todas as prisões.

\section{REFERÊNCIAS}

AYMARD, N.; LHUILIER, D. L'univers pénitenciaire: du côté des surveillants de prison. Paris: Desclée de Brouwer, 1997.

BECCARIA, C. Dos delitos e das penas. São Paulo: Hemus, 1983. 
BENTHAM, J. Teoria das penas legais. São Paulo: Logos, [s. d.].

BITENCOURT, C. Falência da pena de prisão. São Paulo: Revista dos Tribunais, 1993.

BOBBIO, N. A era dos direitos. Rio de Janeiro: Campus, 1992.

BOULLANT, F. Michel Foucault et les prisons. Paris: PUF, 2003.

BRITTO, L. A questão sexual nas prisões. Rio de Janeiro: Jacintho, 1934.

BRUYNE, P. de; HERMAN, J.; SCHOUTHEETE, M. de. Dinâmica da pesquisa em ciências sociais. 5. ed. Rio de Janeiro: Francisco Alves, 1991.

CLEMMER, D. The prison community. New York: Holt, Rinehart and Winston, 1966.

CONFERENCIA NACIONAL DOS BISPOS DO BRASIL. A fraternidade e os encarcerados: Cristo liberta de todas as prisões. São Paulo: Salesiana, 1997.

CONFERÊNCIA NACIONAL DOS BISPOS DO BRASIL. Histórico das CFs (2011-1989). Disponível em: http://www.cnbb.org.br/historico-das-cfs/. Acesso em: 2 jun. 2019a.

CONFERENCIA NACIONAL DOS BISPOS DO BRASIL. Nota da Pastoral Carcerária Nacional sobre o massacre em Altamira. Disponível em: http://www.cnbb.org.br/nota-da-pastoral-carceraria-nacional-sobre-o-massacre-em-altamira/. Acesso em: 2 jun. $2019 \mathrm{~b}$.

CONFERENNCIA NACIONALDOS BISPOS DO BRASIL. Carcerária. Disponível em: http://www.cnbb. org.br/category/pastorais/carceraria/. Acesso em: 2 jun. 2019c.

D’URSO, L. F. B. Direito criminal na atualidade. São Paulo: Atlas, 1999.

FEAUX, V. La culture em milieu carceral - introduction. Actes de colloque organisé à Nivelles. Revue de Droit Pénal et de Criminologie, Bruxelles, p. 673-76, juil. 1991.

FOUCAULT, M. Vigiar e punir. 8. ed. Petrópolis: Vozes, 1991.

FRAGOSO, H. C. Perda da liberdade - os direitos dos presos. In: CONFERÊNCIA NACIONALDA ORDEM DOS ADVOGADOS DO BRASIL, 8., 1980, Manaus. Anais [...]. Manaus: OAB, 1980. p. 759-788.

FRATERNIDADE BRASILEIRA DE ASSISTÊNCIA AOS CONDENADOS. A APAC: o que é? Disponível em: http://www.fbac.org.br/index.php/pt/realidade-atual/o-que-e-apac. Acesso em: 28 maio 2019a.

FRATERNIDADE BRASILEIRA DE ASSISTÊNCIA AOS CONDENADOS. O que é? Disponível em: http://www.fbac.org.br/index.php/pt/o-que-e. Acesso em: 2 jun. $2019 \mathrm{~b}$.

FREI BETO. Apac: o temível direito à liberdade. Disponível em: https://carceraria.org.br/wp-content/ uploads/2018/01/formacao-de-agentes-apac-frei-beto.pdf. Acesso em: 20 mar. 2019.

HOWARD, J. The state of the prison. London: J. M. Dent \& Sons, [s. d.].

MACHADO, B. A.; SLONIAK, M. A. Disciplina ou ressocialização? Racionalidades punitivas, trabalho prisional. Revista Direito GV, São Paulo, v. 11, n. 1, p. 189-222, jan./jun. 2015.

MAYRINK, V. T. S. Vigiar e orar: a gestão de pessoas presas na APAC à luz da genealogia de Foucault. 2018. Tese (Doutorado em Administração) - Pontifícia Universidade Católica de Minas Gerais, Belo Horizonte, 2018. 
OLIVEIRA, L. Não fale do Código de Hamurábi! A pesquisa sócio-jurídica na pós-graduação em Direito. Disponível em: https://edisciplinas.usp.br/pluginfile.php/3932908/mod_resource/content/1/ Hamurabi\%20Luciano\%20Oliveira.pdf. Acesso em: 14 maio 2014.

OTTOBONI, M.; FERREIRA, V. Parceiros da ressurreição. São Paulo: Paulinas, 2004.

ORWELL, G. 1984. 29. ed. São Paulo: Nacional, 2004.

PASTORAL CARCERÁRIA. O que é a Pastoral Carcerária. Disponível em: https://carceraria.org.br/a-pastoral-carceraria\#1541815130503-621cac4b-75d4. Acesso em: 2 jun. 2019a.

PASTORAL CARCERÁRIA. Agenda Nacional pelo Desencarceramento. Disponível em: https://carceraria.org.br/agenda-nacional-pelo-desencarceramento. Acesso em: 3 jun. 2019b.

PASTORAL CARCERÁRIA. Igreja em saída na luta contra o cárcere. Disponível em: https://carceraria.org.br/igreja-em-saida-na-luta-contra-o-carcere. Acesso em: 3 jun. 2019c.

PASTORALCARCERÁRIA. Justiça restaurativa. Disponível em: https://carceraria.org.br/justica-restaurativa. Acesso em: 3 jun. 2019d.

PASTORAL CARCERÁRIA. “Estive preso e vieste me visitar” (Mt 25, 36). Disponível em: https://carceraria.org.br/a-pastoral-carceraria. Acesso em: 3 jun. 2019e.

PIMENTEL, M. P. Sistemas penitenciários. Revista dos Tribunais, São Paulo, v. 639, p. 265-74, jan. 1989.

RESENDE, J. M. Desinstitucionalização prisional e o discurso do método APAC. 2013. Dissertação (Mestrado em Psicologia) - Universidade Federal de Minas Gerais, Belo Horizonte, 2013.

RIO GRANDE DO SUL. Processo 01921-08.04 CODEC/90-5. Requerente: Instituto do Patrimônio Histórico e Artístico do Estado. Localidade: Porto Alegre. Assunto: Tombamento Capela Bom Pastor. [s. d.].

RUSCHE, G.; KIRCHHEIMER, O. Punição e estrutura social. 2. ed. Rio de Janeiro: Revan, 2004.

SANTOS, C. As Associações de Proteção e Assistência ao Condenado (APACs) no estado de Minas Gerais: características e contradições. 2017. Dissertação (Mestrado em Políticas Públicas) - Universidade Federal do Rio Grande do Sul, Porto Alegre, 2017.

SILVA, A. O panóptico no território das APACs. 2014. Dissertação (Mestrado em Gestão Integrada do Território) - Universidade Vale do Rio Doce, Governador Valadares, 2014.

SILVA JUNIOR, A. C. da R. Recuperação religiosa de presos: conversão moral e pluralismo religioso na APAC. 2013. Dissertação (Mestrado em Ciência da Religião) - Universidade Federal de Juiz de Fora, Juiz de Fora, 2013.

SORONDO, F. Os direitos humanos através da história. Porto Alegre: Movimento de Justiça e Direitos Humanos, 1991.

SYKES, G. M. The society of captives: a study of a maximum security prison. New Jersey: Princeton University Press, 2007.

THOMPSON, A. A questão penitenciária. 4. ed. Rio de Janeiro: Forense, 1993. 
VARGAS, L. J.Ó. É possivel humanizar atrás das grades? Uma etnografia do Método de gestão carcerária APAC. 2011. Tese (Doutorado em Antropologia Social) - Universidade de Brasília, 2011.

WESTERN, B. Introduction. In: SYKES, G. M. The society of captives: a study of a maximum security prison. New Jersey: Princeton University Press, 2007. p. IX-XXV.

WOLKMER, A. C. Repensando os direitos humanos desde uma perspectiva latino-americana. In: PINTO, L. G.; WOLKMER, A. C. Justiça e direitos humanos: para uma discussão contemporânea desde a América Latina. Canoas: Unilasalle, 2017.p. 31-42. 